\title{
Controlled Ice Nucleation Using Freeze-Dried Pseudomonas syringae Encapsulated in Alginate Beads
}

\author{
Lindong Weng ${ }^{\mathrm{a}, \mathrm{b}}$, Shannon N. Tessier ${ }^{\mathrm{a}, \mathrm{b}, \mathrm{c}}$, Anisa Swei ${ }^{\mathrm{a}, \mathrm{b}}$, Shannon L. Stott ${ }^{\mathrm{a}, \mathrm{d}, \mathrm{e}}$ and Mehmet Toner ${ }^{\mathrm{a}, \mathrm{b}, \mathrm{c}, *}$ \\ ${ }^{a}$ Center for Engineering in Medicine and BioMEMS Resource Center, Surgical Services, Massachusetts \\ General Hospital, Harvard Medical School, Boston, MA 02129, United States \\ ${ }^{b}$ Department of Surgery, Massachusetts General Hospital, Harvard Medical School, Boston, MA 02114, \\ United States \\ 'Shriners Hospital for Children, Boston, MA 02114, United States \\ ${ }^{d}$ Massachusetts General Hospital Cancer Center, Harvard Medical School, Charlestown, MA 02129, \\ United States \\ ${ }^{\mathrm{e}}$ Department of Medicine, Massachusetts General Hospital, Harvard Medical School, Boston, MA 02114, \\ United States
}

\begin{abstract}
The control of ice nucleation is of fundamental significance in many process technologies related to food and pharmaceutical science and cryobiology. Mechanical perturbation, electromagnetic fields and icenucleating agents (INAs) have been known to induce ice nucleation in a controlled manner. But these ice-nucleating methods may suffer from cumbersome manual operations, safety concerns of external fields, and biocompatibility and recovery issues of INA particles, especially when used in living systems. Given the automatic ice-seeding nature of INAs, a promising solution to overcome some of the above limitations is to engineer a biocomposite that accommodates the INA particles but minimizes their interactions with biologics, as well as enabling the recovery of used particles. In this study, freeze-dried Pseudomonas syringae, a model ice-nucleating agent, was encapsulated into microliter-sized alginate beads. We evaluated the performance of the bacterial hydrogel beads to initiate ice nucleation in water and aqueous glycerol solution by investigating factors including the size and number of the beads and the local concentration of INA particles. In the aqueous sample of a fixed volume, the total mass of the INA particles $(m)$ was found to be the governing parameter that is solely responsible for determining the ice nucleation performance of the bacterial hydrogel beads. The freezing temperature has a strong positive linear correlation with $\log _{10} \mathrm{~m}$. The findings in this study provide an effective, predictable approach to control ice nucleation, which can improve the outcome and standardization of many iceassisted process technologies.
\end{abstract}

Keywords: Heterogeneous ice nucleation; Ice-nucleating bacteria; Pseudomonas syringae; Encapsulation; Hydrogel; Cryopreservation.

\section{Introduction}

Without external nuclei, water and aqueous solutions will maintain a supercooled liquid state well below the melting point until homogeneous ice nucleation occurs. For instance, homogeneous ice nucleation of pure water typically occurs in the range of -35 to $-38^{\circ} \mathrm{C}$, depending on the cooling rate and the sample volume [21]. However, the initiation of ice nucleation at a relatively higher subzero temperature offers many benefits for a wide range of process technologies. For example, during the freeze-drying of food products and pharmaceuticals, controlled ice nucleation with suppressed supercooling can significantly decrease the primary drying time and improve food texturing and product uniformity $[6,7,16]$. In slow-freezing cryopreservation of isolated rat hepatocytes [9] and human oocytes [22], a higher ice nucleation temperature in the extracellular space also reduces the probability of detrimental intracellular ice formation (IIF). As a result, a number of methods have been developed to minimize the supercooling extent (i.e., the difference between the ice nucleation temperature and the

\footnotetext{
* To whom correspondence should be addressed. Email: mehmet toner@hms.harvard.edu
} 
melting point), thereby initiating ice nucleation at high subzero temperatures [16]. For example, mechanical perturbation such as shaking and tapping [10] and irradiation of power ultrasound [13, 26] can be very effective at inducing ice nucleation in the supercooled liquid [16]. It has also been a common practice in cryopreservation to induce ice nucleation in the sample by manually generating a cold spot on the outside of the closed cryogenic container, known as "ice seeding". In addition, magnetic, electric, and electromagnetic fields have been shown to trigger ice nucleation and affect the size of ice crystals and the nucleation rate $[2,18,20]$. A comprehensive review of the approaches to control ice nucleation can be found in the reference [16].

Nevertheless, the current ice-nucleating methods suffer from a number of disadvantages such as the lack of consistency and standardization in the case of manual operations [16], the cumbersome process for a large number of samples [24], and the necessity of electric and/or magnetic fields. To overcome some of these limitations, ice-nucleating agents (INAs) have been extensively explored, such as mineral dust kaolinite [15, 17], silver iodide [3, 23], and bacterium Pseudomonas syringae [19, 24]. It is generally suggested that INAs induce ice nucleation heterogeneously because the microscopic structure of the INA particle surface resembles the ice crystalline structure [24]. For example, silver iodide particles (typically $1 \mu \mathrm{m}$ in diameter) have the same unit cell dimension as ice crystals, being able to induce the freezing of pure water at a temperature up to $-4^{\circ} \mathrm{C}[3,23]$. Due to the highly hydrophilic surface and small size of carbon nanoparticles, they have great potential for enhancing the ice nucleation temperature $[8,25]$. For instance, it was reported that the ice nucleation temperature of a $40 \%$ ethylene glycol solution in the presence of $0.2 \%$ diamond nanoparticles was $-49.2^{\circ} \mathrm{C}$, about 13 degrees higher than the $40 \%$ ethylene glycol alone when subjected to a $1^{\circ} \mathrm{C} / \mathrm{min}$ cooling ramp [8]. Several bacterial strains also serve as biological ice nucleators. The best characterized of these is Pseudomonas syringae, a widely distributed bacterial epiphyte of plants [1]. Our previous study has systematically investigated the ice nucleation kinetics of picoliter-sized drops of heavy water $\left(\mathrm{D}_{2} \mathrm{O}\right)$ and light water $\left(\mathrm{H}_{2} \mathrm{O}\right)$ mixtures with freeze-dried $P$. syringae [24]. The results showed that the median freezing temperature of the $1 \mathrm{mg} / \mathrm{ml} P$. syringae suspension prepared in $100 \% \mathrm{D}_{2} \mathrm{O}$ was as high as $-4.6^{\circ} \mathrm{C}$ [24]. A recent interface-specific sum frequency generation (SFG) spectroscopy and molecular dynamics simulation study revealed that the hydrogen bonds formed at the water-bacterium interface imposed structural ordering on the adjacent water network facilitating ice nucleation [19].

One of the major advantages of INAs is their self-ice-seeding capability, that is heterogeneously initiating ice formation at their characteristic temperatures without manual or instrumental interruptions [24]. But the use of INAs in biological systems may introduce concerns about their biocompatibility, degradability, toxicity, recovery and ease of use. It is therefore desirable to minimize the direct contact between foreign ice nuclei and biological components in order to avoid the potential toxicity and contamination [1]. In addition, the recovery of used INA particles may also facilitate the downstream processing. Hydrogel encapsulation may provide a promising path to realize these ends. The concept of encapsulating ice-nucleating agents within a hydrogel matrix was adopted by Zamecnik et al. [27] to improve the cryopreservation of plant materials in vitro. Their results showed that $10 \mu$ of distilled water containing hydrogel beads embedded with $P$. syringae froze at -2 to $-3^{\circ} \mathrm{C}$, an ice nucleation activity close to that of a free $P$. syringae suspension with $10^{8}-10^{4}$ cells $/ \mathrm{ml}$. However, it was found difficult to count the number of bacterial cells in the hydrogel beads [27], which led to the lack of quantitative characterization. Another drawback of producing bacterial hydrogel beads is the inconvenience of maintaining the bacterial culture [1].

In this study, we encapsulated Snomax particles into microliter-sized alginate beads. Snomax is the freeze-dried form of $P$. syringae, which is readily available and typically used to facilitate snowmaking 
for ski resorts. The ice nucleation performance of the Snomax-laden hydrogel beads was characterized by evaluating factors such as the size and number of the bacterial hydrogel beads and the local Snomax concentration $c_{\text {local }}$ (i.e., the Snomax concentration within the hydrogel matrix). Pure water and aqueous $10 \%$ glycerol solution were chosen as the freezing media. It was found that the total mass of Snomax particles was a governing parameter to determine the ice nucleation ability of the Snomaxladen hydrogel beads in the aqueous sample of a fixed volume.

\section{Materials and Methods}

A certain amount of alginic acid sodium salt (Sigma-Aldrich, St. Louis, MO) was dissolved in cell culture grade water (Gibco WFI for Cell Culture, Thermo Fisher Scientific, Waltham, MA) to prepare a stock solution of $4 \%(\mathrm{w} / \mathrm{v})$ alginate. The Snomax (Snomax International, Englewood, CO) suspension (0.2-30 $\mathrm{mg} / \mathrm{ml}$ ) prepared in WFI water was mixed with an equal volume of the stock alginate solution, yielding a final local concentration of $0.1-15 \mathrm{mg} / \mathrm{ml}$ Snomax and $2 \%(\mathrm{w} / \mathrm{v})$ alginate.

The Snomax-containing alginate solution was loaded into a $3 \mathrm{ml}$ syringe (BD Biosciences, San Jose, CA) which was then mounted vertically onto a GenieTouch Syringe Pump (Kent Scientific Corporation, Torrington, $\mathrm{CT}$ ). As illustrated in Figure 1A, the Snomax-containing alginate solution was then dropped into a $1 \%(\mathrm{w} / \mathrm{v}) \mathrm{CaCl}_{2}$ hardening bath as the syringe pump applied a constant flow rate of $100 \mu \mathrm{l} / \mathrm{min}$. The 30 gauge and 18 gauge flat needles (SAI Infusion Technologies, Libertyville, IL) were used, which have an inner diameter of 0.159 and $0.838 \mathrm{~mm}$, respectively. The alginate beads were gelled in the $\mathrm{CaCl}_{2}$ bath for 30 min with frequent agitation followed by triple washing with WFI water to remove excessive $\mathrm{CaCl}_{2}$ and the Snomax particles on the bead surface. The prepared hydrogel beads were added into 0.5 $\mathrm{ml} \mathrm{WFI} \mathrm{water} \mathrm{contained} \mathrm{in} \mathrm{a} 2 \mathrm{ml}$ cryogenic vial (Corning Glass Works, Corning, NY). For the samples made of $10 \%$ glycerol, the alginate beads were incubated in a stock solution of $10 \%$ glycerol at room temperature for 20 hours on a HulaMixer sample mixer (Life Technologies, Carlsbad, CA) before they were added into $0.5 \mathrm{ml}$ fresh $10 \%$ glycerol solution contained in the cryovial. It was showed previously that the diffusion of glycerol had reached equilibrium across the $1-5 \%(w / v)$ alginate beads after 20 hours [5].

As illustrated in Figure 1B, each aqueous sample contained 1, 5 or 10 beads of a given local Snomax concentration and a given size. The cryovial was placed into a Kryo 560-16 controlled rate freezer (Planer, Middlesex, UK) subjected to a cooling ramp at $1^{\circ} \mathrm{C} / \mathrm{min}$ until freezing. The temperature of each sample was measured by a Type-K thermocouple (Digi-Sense, Cole Parmer Instrument Co., Chicago, IL) that was inserted into the sample through a drilled hole on the cryovial cap. The temperature was recorded every second by a data logger (RDXL6SD, Omega Engineering, Inc., Stamford, CT). It should be noted that in this study the junction of the thermocouple is enclosed in a smooth stainless steel sheath of $2.5 \mathrm{~mm}$ in diameter. Our preliminary study found that when an exposed thermocouple junction was immersed into the liquid, air bubbles might adsorb to the junction and serve as an ice nucleation site, causing uncontrolled and spontaneous freezing [11]. Once ice nucleates in the aqueous sample, the temperature will return to the melting point and then follow the liquidus curve. As seen in Figure $1 \mathrm{C}$, the ice nucleation temperature or the freezing temperature $\left(T_{f}\right)$ can be identified when an abrupt increase appears in the temperature profile. A total of 8-16 replicates were measured for each experimental condition.

\section{Results and Discussion \\ Morphology of Snomax-laden alginate beads}

A range of alginate beads were prepared in this study. Figure 1D shows two examples that were prepared by the 18 gauge needle and had a local Snomax concentration of $0.1 \mathrm{mg} / \mathrm{ml}$ and $15 \mathrm{mg} / \mathrm{ml}$, 
respectively. As expected, a higher $c_{\text {local }}$ of Snomax particles contributed to less transparency of the hydrogel beads. Table 1 summarizes the size of the alginate beads that had different local concentrations of Snomax and were generated by the 30-gauge or 18-gauge needle. With the same $c_{\text {local }}$, the beads generated by the 18-gauge needle are around 3.5 times as large as those generated by the 30 gauge needle in terms of volume. When the same needle size was used, a higher local concentration of Snomax led to a smaller bead volume. This is mainly because a smaller volume is needed for the gravity to overcome the surface tension at the tip of the needle if the local concentration of solid particles is higher. The size of the prepared bacterial hydrogel beads enables easy removal of used INA particles, which may benefit the downstream processing. To illustrate the effect of freezing on the hydrogel structure, Figure $1 \mathrm{E}$ and $\mathrm{F}$ compared the morphologies of Snomax-free beads before and after they were freeze-thawed. It is clear that the freeze-thawed alginate bead (Figure 1F) is still intact but has a wrinkled surface, which is very similar to those treated by the freeze-drying or air drying process $[12,14]$. This wrinkling phenomenon has been suggested to result from the partial collapse of the polymer network due to the loss of water content during ice formation or evaporation [12, 14].

\section{Ice nucleation in WFI water facilitated by Snomax-Iaden alginate beads}

Figure 2 shows the freezing temperature of WFI water in the presence of Snomax-laden alginate beads of different $c_{\text {local }}$ (i.e., $0.1,2.5$ or $15 \mathrm{mg} / \mathrm{ml}$ ). Given the stochastic nature of ice nucleation, we presented the data points of all replicates and indicated the median freezing temperature $\left(T_{f}^{\text {median }}\right)$ and the interquartile range. In general, the freezing temperature is positively related to three parameters under investigation: the number of beads $(N)$, the volume of beads $(V)$, and the local Snomax concentration $\left(c_{\text {local }}\right)$. It can be seen in Figure $2 \mathrm{~A}$ that the presence of a single bead prepared by the 30gauge needle and containing $0.1 \mathrm{mg} / \mathrm{ml}$ Snomax induced the ice nucleation at $-5.6^{\circ} \mathrm{C}$ whereas the median freezing temperature increased to $-4.5^{\circ} \mathrm{C}$ with the addition of four more beads of the same size and $c_{\text {local }}$. As for the effect of $V$, five beads that were prepared by the 30 -gauge needle and contained $2.5 \mathrm{mg} / \mathrm{ml}$ Snomax led to a median freezing temperature of $-4.0^{\circ} \mathrm{C}$. But when the beads were generated by the 18-gauge needle, therefore more than three times as large as their 30-gauge counterparts, the $T_{f}^{\text {median }}$ increased to $-3.4^{\circ} \mathrm{C}$. As seen in Figure $2 \mathrm{~B}$, the presence of ten beads generated by the 18-gauge needle and containing $0.1 \mathrm{mg} / \mathrm{ml}$ Snomax led to a median freezing temperature of $-3.7^{\circ} \mathrm{C}$. When the local Snomax concentration increased to $15 \mathrm{mg} / \mathrm{ml}$, the median freezing temperature became $-3.3^{\circ} \mathrm{C}$. Table 2 shows that the median freezing temperature of $0.5 \mathrm{ml} \mathrm{WFI}$ water alone is $-8.0^{\circ} \mathrm{C}$ while the $T_{f}^{\text {median }}$ of $0.5 \mathrm{ml} \mathrm{WFI}$ water containing ten Snomax-free alginate beads prepared by the 18-gauge needle is $-7.2^{\circ} \mathrm{C}$. Since almost all the data points shown in Figure 2 are higher than $-7^{\circ} \mathrm{C}$, the Snomax particles played a major role in enhancing the ice nucleation temperature even though they were confined within a hydrogel matrix.

\section{Ice nucleation in $10 \%$ glycerol facilitated by Snomax-laden alginate beads}

We also investigated the freezing phenomenon in aqueous $10 \%$ glycerol solution that was facilitated by the Snomax-laden alginate beads. Glycerol is one of the most commonly used cryoprotectants due to its colligative property, strong hydrogen-bonding ability, and high viscosity at low temperatures [4]. As seen in Figure 3, the freezing temperature of $10 \%$ glycerol in the presence of alginate beads of different $c_{\text {local }}$ and different sizes presents the similar trends to those found in Figure 2. The addition of the solute glycerol did not change the positive relationship between the freezing temperature and $N, V$, or $c_{\text {local }}$. Figure 3A shows that the presence of a single bead prepared by the 30 -gauge needle and containing 0.1 $\mathrm{mg} / \mathrm{ml}$ Snomax led to the ice nucleation at $-10.0^{\circ} \mathrm{C}$ while the median freezing temperature increased to $-8.7{ }^{\circ} \mathrm{C}$ with the addition of nine more beads of the same $V$ and $c_{\text {local }}$. It is also shown that the five beads that contained $2.5 \mathrm{mg} / \mathrm{ml}$ Snomax and were prepared by the 30-gauge needle contributed to a 
median freezing temperature of $-7.0^{\circ} \mathrm{C}$. When the beads were prepared by the 18-gauge needle, the $T_{f}^{\text {median }}$ increased to $-6.4^{\circ} \mathrm{C}$. Figure $3 \mathrm{~B}$ shows that the addition of ten beads each containing $0.1 \mathrm{mg} / \mathrm{ml}$ Snomax generated a median freezing temperature of $-7.5^{\circ} \mathrm{C}$. However, when the beads contained 15 $\mathrm{mg} / \mathrm{ml}$ Snomax, the median freezing temperature increased to $-6.1^{\circ} \mathrm{C}$. As summarized in Table 3 , the median freezing temperature of $0.5 \mathrm{ml} \mathrm{10 \%} \mathrm{glycerol} \mathrm{containing} \mathrm{neither} \mathrm{Snomax} \mathrm{nor} \mathrm{hydrogel} \mathrm{beads} \mathrm{is} \mathrm{-}$ $11.8^{\circ} \mathrm{C}$. The $T_{f}^{\text {median }}$ of $0.5 \mathrm{ml} 10 \%$ glycerol having ten Snomax-free alginate beads prepared by the 18 gauge needle is $-11.1^{\circ} \mathrm{C}$. All the data points shown in Figure 3 are above $-11^{\circ} \mathrm{C}$. Therefore, it is the Snomax particles that significantly enhanced the freezing temperature of the aqueous system.

\section{Ice nucleation performance parameter}

There are multiple factors able to affect the ice nucleation of the aqueous samples containing Snomaxladen hydrogel beads. One may obtain the same freezing temperature by employing different combinations of $N, V$ and $c_{\text {local }}$. Therefore, it will be highly instructive to provide a universal parameter that is solely responsible for determining the freezing temperature. In this study, we identified the total mass of the Snomax particles contained by the aqueous sample of a fixed volume to be such a parameter. In Figure 4, the freezing temperature has been plotted as a function of the total mass of Snomax $\left(m=N \cdot V \cdot c_{\text {local }}\right.$, in a $\log 10$ scale) existing in $0.5 \mathrm{ml} \mathrm{WFI} \mathrm{water.} \mathrm{We} \mathrm{also} \mathrm{measured} \mathrm{the}$ freezing temperatures of suspensions of free Snomax particles ranging from 0.005 to $100 \mathrm{mg} / \mathrm{ml}$ prepared in WFI water (black data points in Figure 4). It is evident that all the data points shown in Figure 4 share the same trend. The Pearson's correlation between $T_{f}$ and $\log _{10} m$ yields a coefficient $(r)$ of 0.9497 , suggesting a clear positive linear relationship between $T_{f}$ and $\log _{10} m$. The curve that best fits all the data points is $T_{f}=0.6478 \cdot \log _{10} m-3.052\left(R^{2}=0.9019\right)$. This demonstrates that the total mass of Snomax is the parameter to dictate the occurrence of ice nucleation in $0.5 \mathrm{ml}$ WFI water regardless of the form of presence of the INA particles, either in a suspension or in a confined space. In Figure 5, we plotted the freezing temperatures shown in Figure 3, together with the freezing temperatures of the Snomax suspensions $(0.005$ to $50 \mathrm{mg} / \mathrm{ml}$ ) prepared in aqueous $10 \%$ glycerol solution (black data points in Figure 5), as a function of $m$ in $\log 10$ scale. All the data points follow the same trend very well with a Pearson's correlation coefficient of 0.9783 , suggesting a strong positive linear relationship between $T_{f}$ and $\log _{10} m$. The curve described by $T_{f}=1.093 \cdot \log _{10}(m)-5.771\left(R^{2}=0.9571\right)$ is the best fit to all the data points shown in Figure 5 . It is indicated that the addition of solute did not change the role of the total mass of INA particles as the governing parameter. Therefore, we suggest that one can increase the total mass of INA particles by adjusting the combination of $N, V$ and $c_{\text {local }}$ to enhance the ice nucleation temperature.

The experimental conditions investigated so far used identical sample volume $\left(V_{\text {sample }}\right)$ of $0.5 \mathrm{ml}$. To investigate the effect of the sample volume on the freezing temperature, Table 4 compares the freezing temperatures of the $0.5 \mathrm{ml}$ and $1.5 \mathrm{ml}$ samples, both of which contain five alginate beads encapsulating $2.5 \mathrm{mg} / \mathrm{ml}$ Snomax (i.e., having the same total mass). Although $0.5 \mathrm{ml}$ samples have a slightly higher median freezing temperature than their $1.5 \mathrm{ml}$ counterparts, the unpaired $t$ test revealed that there is no statistical difference in the freezing temperature $\left(T_{f}\right)$ between the $0.5 \mathrm{ml}$ and $1.5 \mathrm{ml}$ groups, with the only exception for the condition of five beads (30 gauge) in WFI ( $p=0.0433)$. In the latter case, more replicates might be necessary to evaluate the difference more accurately since the combination of WFI and less Snomax contributes to a wider range of data points than either $10 \%$ glycerol or more Snomax in WFI. Given such uncertainty, in the current study we conclude that in the case of a constant sample volume the total mass of Snomax is mostly responsible for dictating the ice nucleation temperature. 


\section{Conclusions}

Although the controlled ice nucleation can benefit multiple process technologies, the ice-nucleating methods available so far suffer from a few disadvantages, especially when employed in biological systems. In this study, we encapsulated freeze-dried $P$. syringae into hydrogel beads to develop a controllable, effective ice-nucleating approach that can minimize the interaction between the INA particles and the biological system and enables the removal of used particles from the biological system. Due to the self-ice-seeding nature of INAs, our approach does not require manual interruption or external fields. For this study, the ice nucleation performance of these bacterial hydrogel beads was characterized. In the aqueous sample of a fixed volume, the total mass of the INA particles was identified as a universal parameter that dictates the ice nucleation temperature. The findings presented here provide the guidance to tune the ice nucleation temperature within a 6-degree window or even larger by adjusting the size and number of bacterial hydrogel beads and the local INA concentration. The ice-nucleating approach proposed in this study can improve the outcome and standardization of many ice-assisted process technologies such as the slow-freezing cryopreservation of stem cells for regenerative medicine, cellular therapies, and drug screening.

\section{Acknowledgements}

This work was supported by grants DoD DHP SBIR H151-013-0141 and NIH P41 EB002503. S.N.T. holds a Natural Sciences and Engineering Research Council (NSERC) of Canada Postdoctoral Fellowship.

\section{References}

[1] N. Cochet, P. Widehem, Ice crystallization by Pseudomonas syringae, Appl Microbiol Biotechnol, 54 (2000) 153-161.

[2] M. Dalvi-Isfahan, N. Hamdami, E. Xanthakis, A. Le-Bail, Review on the control of ice nucleation by ultrasound waves, electric and magnetic fields, J. Food Eng., 195 (2017) 222-234.

[3] G. Edwards, L. Evans, V. La Mer, Ice nucleation by monodisperse silver iodide particles, J Colloid Sci, 17 (1962) 749-758.

[4] B.J. Fuller, Cryoprotectants: the essential antifreezes to protect life in the frozen state, Cryo Letters, 25 (2004) 375-388.

[5] I. Garbayo, R. León, C. Vílchez, Diffusion characteristics of nitrate and glycerol in alginate, Colloids Surf., B, 25 (2002) 1-9.

[6] R. Geidobler, I. Konrad, G. Winter, Can Controlled Ice Nucleation Improve Freeze-Drying of HighlyConcentrated Protein Formulations?, J. Pharm. Sci., 102 (2013) 3915-3919.

[7] R. Geidobler, G. Winter, Controlled ice nucleation in the field of freeze-drying: fundamentals and technology review, Eur. J. Pharm. Biopharm., 85 (2013) 214-222.

[8] X. Han, H. Ma, C. Wilson, J. Critser, Effects of nanoparticles on the nucleation and devitrification temperatures of polyol cryoprotectant solutions, Microfluid Nanofluidics, 4 (2008) 357-361.

[9] C.L. Harris, M. Toner, A. Hubel, E.G. Cravalho, M.L. Yarmush, R.G. Tompkins, Cryopreservation of isolated hepatocytes: intracellular ice formation under various chemical and physical conditions, Cryobiology, 28 (1991) 436-444.

[10] P. Hobbs, Ice Physics, Clarendon Press, Oxford, 1974.

[11] A. Holowczenko, S.A. Schoch, H.W. Sibley, Water freezing enhancement for thermal storage brine tube, United States Patent, 1988.

[12] S. Hua, H. Ma, X. Li, H. Yang, A. Wang, pH-sensitive sodium alginate/poly (vinyl alcohol) hydrogel beads prepared by combined $\mathrm{Ca} 2+$ crosslinking and freeze-thawing cycles for controlled release of diclofenac sodium, Int. J. Biol. Macromolec., 46 (2010) 517-523. 
[13] H. Kiani, D.-W. Sun, A. Delgado, Z. Zhang, Investigation of the effect of power ultrasound on the nucleation of water during freezing of agar gel samples in tubing vials, Ultrason Sonochem, 19 (2012) 576-581.

[14] J. Lee, D. Cha, H.J. Park, Survival of freeze-dried Lactobacillus bulgaricus KFRI 673 in chitosan-coated calcium alginate microparticles, J. Agric. Food Chem, 52 (2004) 7300-7305.

[15] F. Lüönd, O. Stetzer, A. Welti, U. Lohmann, Experimental study on the ice nucleation ability of sizeselected kaolinite particles in the immersion mode, J Geophys Res-Atmos, 115 (2010).

[16] G.J. Morris, E. Acton, Controlled ice nucleation in cryopreservation-a review, Cryobiology, 66 (2013) 85-92.

[17] B. Murray, D. O'sullivan, J. Atkinson, M. Webb, Ice nucleation by particles immersed in supercooled cloud droplets, Chem. Soc. Rev., 41 (2012) 6519-6554.

[18] M. Orlowska, M. Havet, A. Le-Bail, Controlled ice nucleation under high voltage DC electrostatic field conditions, Food Res Int, 42 (2009) 879-884.

[19] R. Pandey, K. Usui, R.A. Livingstone, S.A. Fischer, J. Pfaendtner, E.H. Backus, Y. Nagata, J. FröhlichNowoisky, L. Schmüser, S. Mauri, Ice-nucleating bacteria control the order and dynamics of interfacial water, Sci. Adv., 2 (2016) e1501630.

[20] A. Petersen, H. Schneider, G. Rau, B. Glasmacher, A new approach for freezing of aqueous solutions under active control of the nucleation temperature, Cryobiology, 53 (2006) 248-257.

[21] B. Riechers, F. Wittbracht, A. Hütten, T. Koop, The homogeneous ice nucleation rate of water droplets produced in a microfluidic device and the role of temperature uncertainty, Phys Chem Chem Phys, 15 (2013) 5873-5887.

[22] F.S. Trad, M. Toner, J.D. Biggers, Effects of cryoprotectants and ice-seeding temperature on intracellular freezing and survival of human oocytes, Hum Reprod, 14 (1999) 1569-1577.

[23] B. Vonnegut, The nucleation of ice formation by silver iodide, J. Appl. Phys., 18 (1947) 593-595.

[24] L. Weng, S.N. Tessier, K. Smith, J.F. Edd, S.L. Stott, M. Toner, Bacterial Ice Nucleation in Monodisperse D2O and H2O-in-Oil Emulsions, Langmuir, 32 (2016) 9229-9236.

[25] T.F. Whale, M. Rosillo-Lopez, B.J. Murray, C.G. Salzmann, Ice Nucleation Properties of Oxidized Carbon Nanomaterials, J. Phys. Chem. Lett., 6 (2015) 3012-3016.

[26] B. Xu, M. Zhang, B. Bhandari, X. Cheng, Influence of power ultrasound on ice nucleation of radish cylinders during ultrasound-assisted immersion freezing, Int. J. Refrig., 46 (2014) 1-8.

[27] J. Zamecnik, V. Skladal, V. Kudela, Ice nucleation by immobilized ice nucleation active bacteria, Cryo Letters, 12 (1991) 149-154. 
A

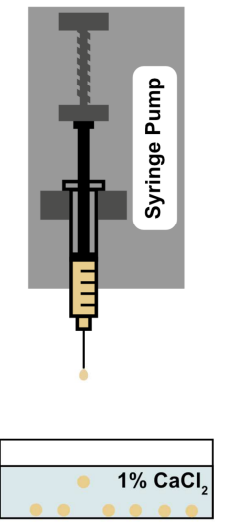

B

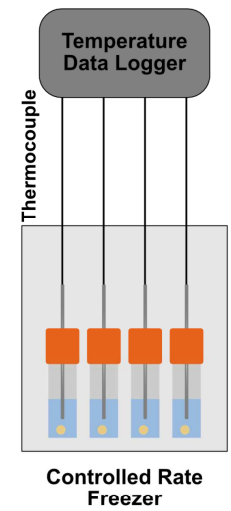

C
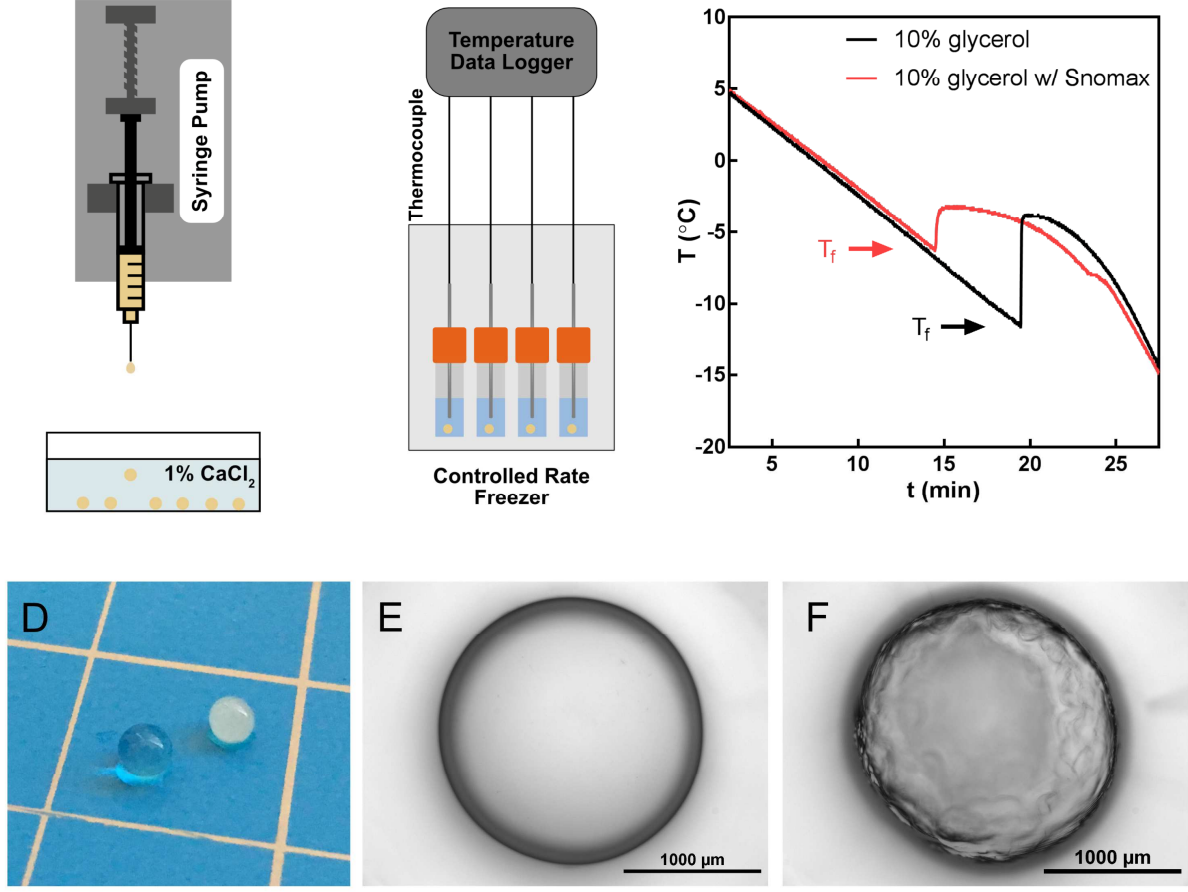

Figure $1 \mathrm{~A}$. The preparation of alginate beads by the ionotropic gelation method using calcium chloride as a crosslinking agent. B. The freezing temperature measurement of a $0.5 \mathrm{ml}$ aqueous sample subjected to the $1^{\circ} \mathrm{C} / \mathrm{min}$ cooling ramp. C. The temperature profiles of $0.5 \mathrm{ml} 10 \%$ glycerol solution alone (black) and $0.5 \mathrm{ml} 10 \%$ glycerol containing ten alginate beads (prepared by 18 gauge needle) and encapsulating $15 \mathrm{mg} / \mathrm{ml}$ Snomax (red). D. Two alginate beads prepared by 18 gauge needle and encapsulating 0.1 $\mathrm{mg} / \mathrm{ml}$ (left) and $15 \mathrm{mg} / \mathrm{ml}$ (right) Snomax, respectively. The grid has a dimension of $12.7 \mathrm{~mm} \times 12.7 \mathrm{~mm}$. E. A Snomax-free alginate bead before frozen. F. A Snomax-free alginate bead after freeze-thawed.

A

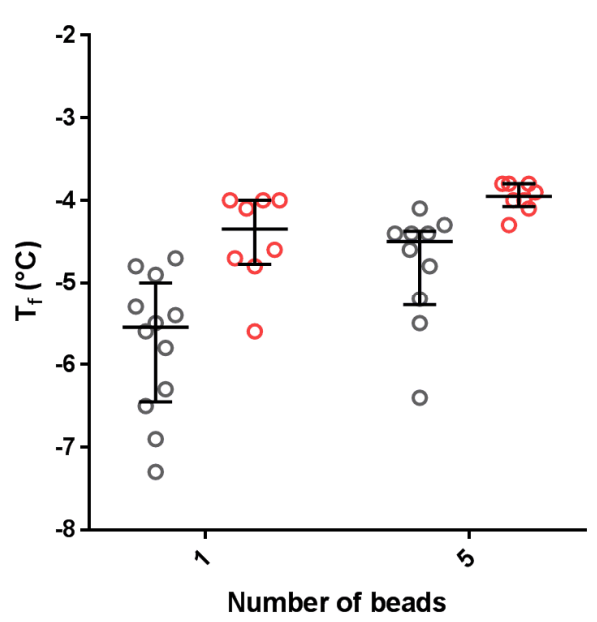

B

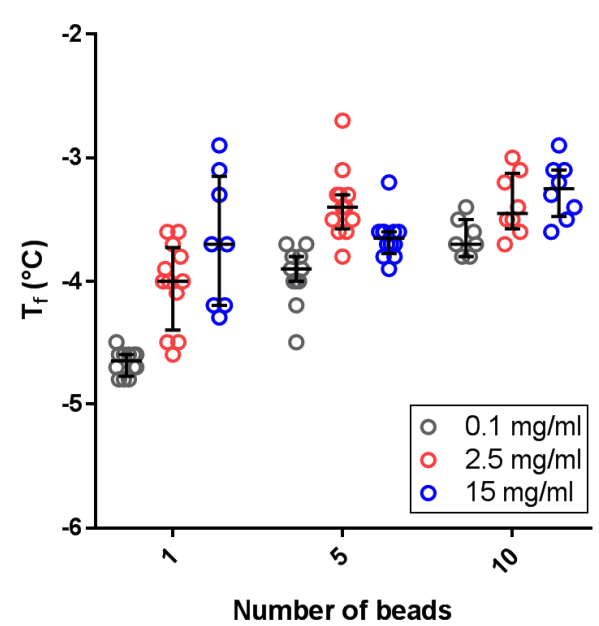


Figure 2. The freezing temperature $\left(T_{f}\right)$ of WFI water in the presence of alginate beads of different sizes and containing different local concentrations of Snomax $(0.1,2.5$, or $15 \mathrm{mg} / \mathrm{ml})$. A: The beads were generated by a 30 gauge needle; $\mathrm{B}$ : The beads were generated by an 18 gauge needle.

A

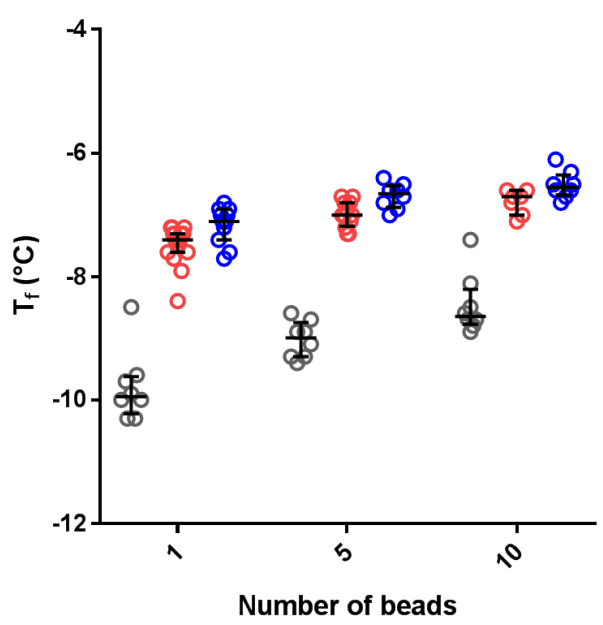

B

18-Gauge

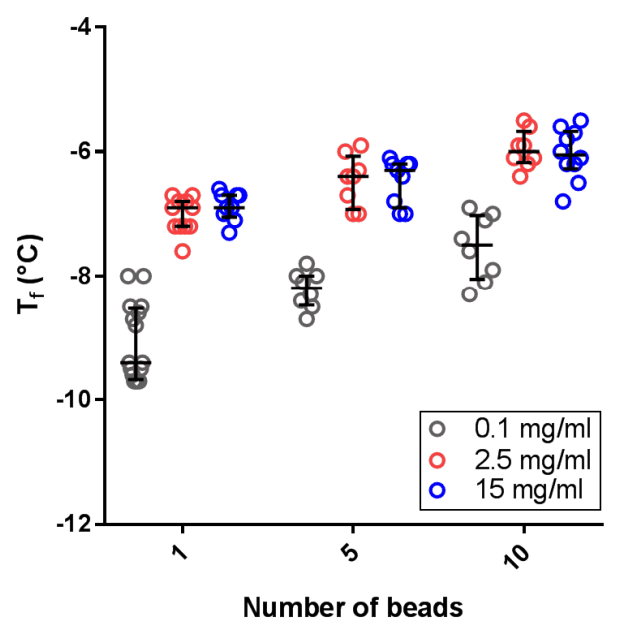

Figure 3. The freezing temperature $\left(T_{f}\right)$ of aqueous $10 \%$ glycerol in the presence of alginate beads of different sizes and containing different local concentrations of Snomax $(0.1,2.5$, or $15 \mathrm{mg} / \mathrm{ml})$. A: The beads were generated by a 30 gauge needle; $\mathrm{B}$ : The beads were generated by an 18 gauge needle.

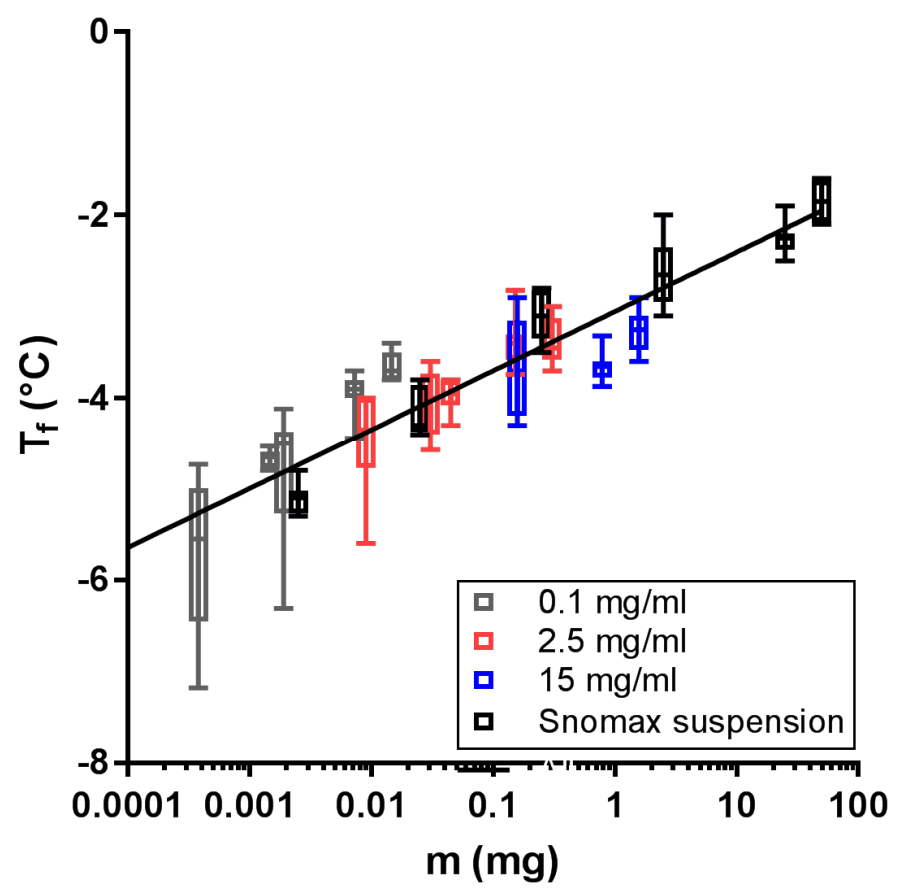


Figure 4. The freezing temperature $\left(T_{f}\right)$ profile that is plotted as a function of the total mass of Snomax $(m)$ existing in $0.5 \mathrm{ml} \mathrm{WFI} \mathrm{water.} \mathrm{The} \mathrm{black} \mathrm{data} \mathrm{points} \mathrm{correspond} \mathrm{to} \mathrm{the} \mathrm{freezing} \mathrm{temperatures} \mathrm{of} \mathrm{the}$ Snomax suspensions of $0.005-100 \mathrm{mg} / \mathrm{ml}$. The curve that best fits all the data points is $T_{f}=0.6478$. $\log _{10} m-3.052\left(R^{2}=0.9019\right)$ as represented by the solid line.

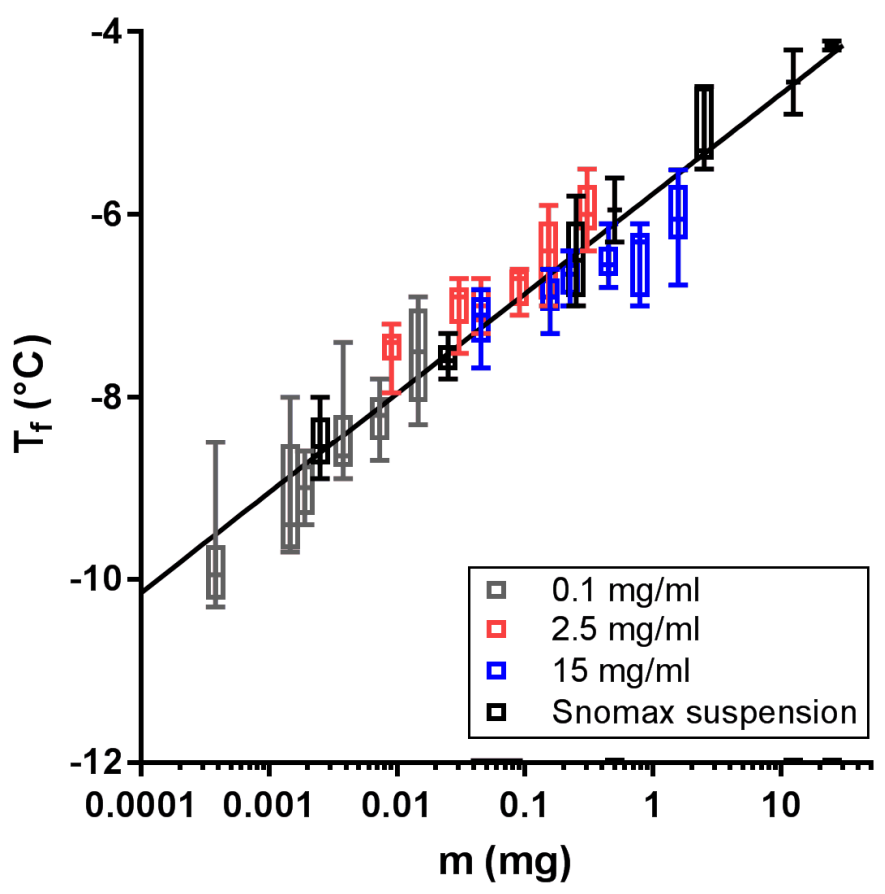

Figure 5. The freezing temperature $\left(T_{f}\right)$ profile that is plotted as a function of the total mass of Snomax $(\mathrm{m})$ existing in $0.5 \mathrm{ml}$ aqueous $10 \%$ glycerol. The black data points represent the freezing temperatures of the Snomax suspensions of $0.005-50 \mathrm{mg} / \mathrm{ml}$ prepared in $10 \%$ glycerol. The solid line described by $T_{f}=1.093 \cdot \log _{10}(m)-5.771$ is the best fit to all the data points $\left(R^{2}=0.9571\right)$. 
358

359

360

Table 1. The diameter $(D)$ and volume $(V)$ of the alginate beads containing different local concentrations $\left(c_{\text {local }}\right)$ of Snomax generated by the 30 gauge or 18 gauge needle

\begin{tabular}{ccccc} 
& \multicolumn{2}{c}{$D(\mathrm{~mm})$} & \multicolumn{2}{c}{$V(\mu \mathrm{l})$} \\
\cline { 2 - 5 }$c_{\text {local }}(\mathrm{mg} / \mathrm{ml})$ & 30 -gauge & 18 -gauge & 30 -gauge & 18 -gauge \\
\hline 0 & $1.91 \pm 0.03$ & $2.92 \pm 0.05$ & $3.7 \pm 0.2$ & $13.1 \pm 0.6$ \\
0.1 & $1.94 \pm 0.05$ & $3.03 \pm 0.03$ & $3.8 \pm 0.3$ & $14.6 \pm 0.5$ \\
2.5 & $1.89 \pm 0.04$ & $2.86 \pm 0.02$ & $3.6 \pm 0.2$ & $12.2 \pm 0.3$ \\
15 & $1.78 \pm 0.02$ & $2.71 \pm 0.05$ & $3.0 \pm 0.1$ & $10.5 \pm 0.5$ \\
\hline
\end{tabular}

Table 2. The freezing temperature $\left(T_{f}\right)$ of $0.5 \mathrm{ml} \mathrm{WFI} \mathrm{water} \mathrm{in} \mathrm{the} \mathrm{absence} \mathrm{of} \mathrm{any} \mathrm{beads} \mathrm{or} \mathrm{containing} \mathrm{ten}$ Snomax-free beads

\begin{tabular}{cccc}
\hline & \multicolumn{3}{c}{$T_{f}$} \\
\cline { 2 - 4 } & $\mathrm{WFI}$ & $\mathrm{WFI}$ w/ 10 beads (30 gauge) & $\mathrm{WFI}$ w/ 10 beads (18 gauge) \\
\hline Median & $-8.0^{\circ} \mathrm{C}$ & $-8.1^{\circ} \mathrm{C}$ & $-7.2^{\circ} \mathrm{C}$ \\
(Min, Max $)$ & $\left(-9.8^{\circ} \mathrm{C},-7.2^{\circ} \mathrm{C}\right)$ & $\left(-8.8^{\circ} \mathrm{C},-8.1^{\circ} \mathrm{C}\right)$ & $\left(-7.5^{\circ} \mathrm{C},-7.0^{\circ} \mathrm{C}\right)$
\end{tabular}

Table 3. The freezing temperature $\left(T_{f}\right)$ of $0.5 \mathrm{ml}$ aqueous $10 \%$ glycerol in the absence of any beads or containing ten Snomax-free beads

\begin{tabular}{cccc}
\hline & \multicolumn{3}{c}{$T_{f}$} \\
\cline { 2 - 4 } & $10 \%$ glycerol & $\begin{array}{c}10 \% \text { glycerol w/ } 10 \text { beads } \\
\text { (30 gauge) }\end{array}$ & $\begin{array}{c}10 \% \text { glycerol w/ 10 beads } \\
\text { (18 gauge) }\end{array}$ \\
\hline Median & $-11.8^{\circ} \mathrm{C}$ & $-11.5^{\circ} \mathrm{C}$ & $-11.1^{\circ} \mathrm{C}$ \\
(Min, Max $)$ & $\left(-13.0^{\circ} \mathrm{C},-10.4^{\circ} \mathrm{C}\right)$ & $\left(-12.0^{\circ} \mathrm{C},-10.9^{\circ} \mathrm{C}\right)$ & $\left(-11.8^{\circ} \mathrm{C},-10.6^{\circ} \mathrm{C}\right)$
\end{tabular}

Table 4. The effect of the sample volume $\left(V_{\text {sample }}\right)$ on the freezing temperature $\left(T_{f}\right)$. The local concentration of Snomax was $2.5 \mathrm{mg} / \mathrm{ml}$ and five beads were added into each sample.

\begin{tabular}{|c|c|c|c|c|}
\hline \multirow{2}{*}{ Medium } & \multirow{2}{*}{$\begin{array}{l}\text { Needle } \\
\text { size }\end{array}$} & \multicolumn{2}{|c|}{ Median (Min, Max) $/{ }^{\circ} \mathrm{C}$} & \multirow{2}{*}{$p$-value } \\
\hline & & $V_{\text {sample }}=0.5 \mathrm{ml}$ & $V_{\text {sample }}=1.5 \mathrm{ml}$ & \\
\hline \multirow{2}{*}{ WFI } & 30 gauge & $-4.0(-4.3,-3.8)$ & $-4.2(-4.4,-3.9)$ & 0.0433 \\
\hline & 18 gauge & $-3.4(-3.8,-2.7)$ & $-3.6(-3.9,-3.3)$ & 0.0582 \\
\hline \multirow{2}{*}{$\begin{array}{c}10 \% \\
\text { glycerol }\end{array}$} & 30 gauge & $-7.0(-7.3,-6.7)$ & $-7.3(-7.4,-6.9)$ & 0.0527 \\
\hline & 18 gauge & $-6.4(-7.0,-5.9)$ & $-6.7(-7.6,-6.5)$ & 0.0817 \\
\hline
\end{tabular}




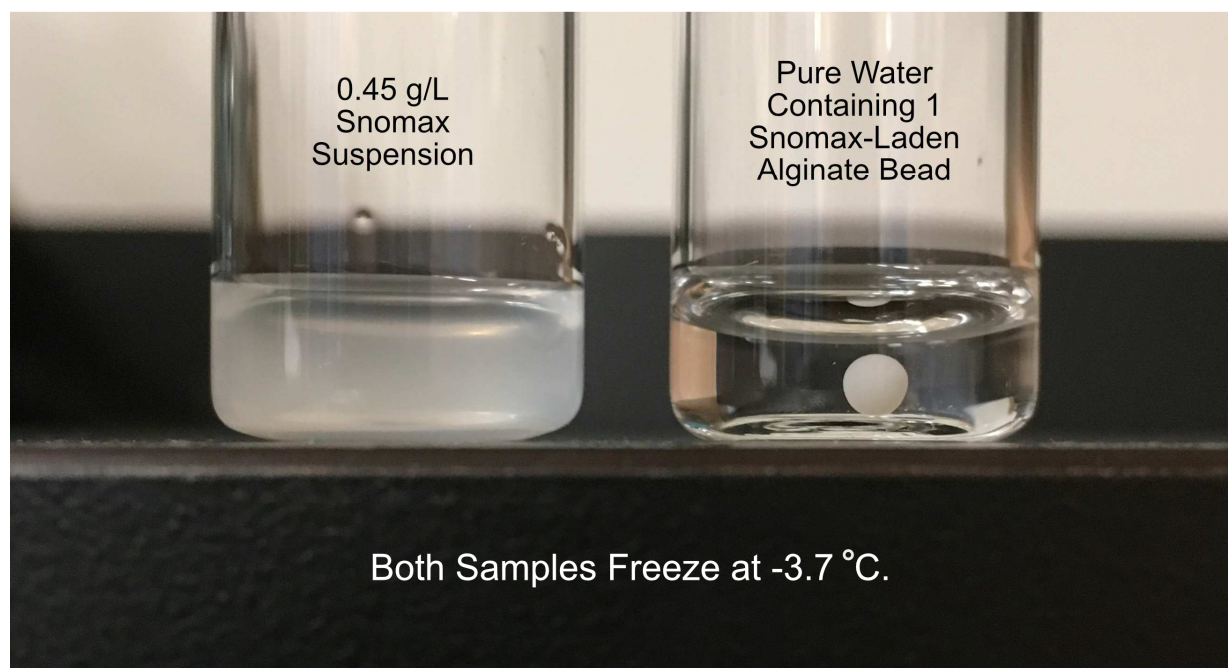

